\title{
AVALIAÇÃO DA ALTERAÇÃO DE COR DE RESINAS COMPOSTAS EM CONTATO COM SOLUÇÕES POTENCIALMENTE CORANTES
}

\section{EVALUATION OF COMPOSITE RESIN COLOR ALTERATION IN CONTACT WITH STAINING SOLUTIONS}

\author{
Stella Kossatz Pereira ${ }^{1}$, Andressa Aparecida Müller², \\ Andrezza Caldeira Boratto ${ }^{2}$, Paula Moro Veiga ${ }^{2}$ \\ 1 Autor para contato: Universidade Estadual de Ponta Grossa - UEPG, Campus em \\ Uvaranas, Departamento de Odontologia, Ponta Grossa, PR, Brasil; \\ e-mail: stellakp@ig.com.br; (42) 220-3111 e Universidade Paranaense - UNIPAR, \\ Umuarama, PR \\ 2 Universidade Estadual de Ponta Grossa, Campus em Uvaranas, Departamento de \\ Odontologia, Ponta Grossa, PR, Brasil
}

Recebido para publicação em 16/04/2003

Aceito para publicação em 07/05/2003

\section{RESUMO}

A grande dificuldade nos dias atuais é encontrar uma resina composta que não cause pigmentação nas restaurações estéticas. Diante disso, propusemos um trabalho que possibilite a visualização da alteração de cor de três resinas compostas: Charisma (Heraeus- Kulzer), Durafill VS (Heraeus-Kulzer) e Fill Magic Condensável (Vigodent), em contato direto com soluções corantes em determinado período de tempo. Para a realização deste trabalho foram confeccionados 25 corposde-prova de cada resina composta, em uma matriz metálica, e, após a polimerização por 40 segundos, estes foram divididos em 5 corpos-de-prova para cada solução corante, sendo estas: café, vinho tinto, chá mate, Coca-Cola® e água destilada (grupo controle). As amostras foram analisadas por três examinadores previamente calibrados, de acordo com a escala de cor das resinas compostas e sob luz artificial fluorescente, no período de 1, 24, 72 horas e 1 semana a partir da data de imersão. Para a realização dos resultados foram estabelecidos escores que variaram de 0 a 5 , e através destes concluiu-se que a solução de café foi a que apresentou um maior grau de manchamento na resina de micropartícula Durafill VS (Heraeus-Kulzer) em relação às outras resinas compostas.

Palavras-chave: resinas compostas, alteração de cor, corantes

\section{ABSTRACT}

A great difficulty for dentists is to find a composite resin that does not cause pigmentation in static restorations. With this fact in mind, we developed a study 
that enabled us to visualize color alteration in three composite resins: Charisma (Heraeus-Kulzer), Durafill VS (Heraeus-Kulzer) and Condensable Fill Magic (Vigodent), in direct contact with solutions of staining substances such as coffee, red wine, tea, coke and distilled water (control group). The samples were analysed by means of three previously calibrated examinators, according to the color scale of the composite resins, under artificial fluorescent light, in one, twenty-four, seventytwo hour periods and a one week period, starting from the date of immersion. Scores from 0 to 5 were established for the analysis of the results, and we concluded that coffee is the substance that presents the highest micro-particle resin staining power as compared to the other solutions.

Key words: composite resin, color alteration, staining substances

\section{Introdução}

A estética sempre foi uma das grandes preocupações da odontologia restauradora. Atualmente a procura da sociedade por um tratamento de maior qualidade e mais duradouro, intensificada pela exposição dos "sorrisos perfeitos" pela mídia, tem colocado a odontologia estética como um grande desafio. As restaurações, com o passar do tempo, tendem a sofrer alterações na sua coloração devido à ingestão de alimentos corantes pelo paciente, causando o desequilíbrio estético do sorriso.

As resinas compostas encontram-se disponíveis na profissão odontológica há aproximadamente 35 anos, pois no final dos anos 50, Ray Bowen (1963) iniciou seus experimentos reforçando resinas epóxicas com partículas de carga. A partir de 1979, com as resinas compostas híbridas, foi possível aumentar a quantidade de carga inorgânica (80\%) e reduzir satisfatoriamente a contração de polimerização, sorção de água, expansão térmica e desgaste superficial (MENEZES et al., 1999).

Os materiais restauradores submetidos ao agressivo ambiente oral, associado aos mais variados tipos de alimentos e produtos de fermentação, muitas vezes acompanhados de corantes, induzem as restaurações aos manchamentos e alterações superficiais em curto período de tempo (DINELLI et al., 1995).

É importante que o cirurgião-dentista tenha conhecimento das diferentes formas de aplicação das resinas compostas, sendo capaz de selecionar o melhor material e a técnica restauradora apropria- da em diferentes situações clínicas.

Segundo Maixner e Susin (2001) o tempo de permanência da resina composta na cavidade oral, o grau de polimerização, a técnica de fotopolimerização, a técnica de acabamento e polimento da restauração, o contato imediato com alimentos e substâncias corantes e o acúmulo da placa bacteriana são as principais causas da descoloração desses materiais.

O manchamento superficial das resinas compostas está relacionado com a penetração de corantes contidos nos alimentos através da superfície da restauração. Baratieri (1992), também considera a higiene oral um fator preponderante na estabilidade de cor, visto que a presença da placa bacteriana e de seus produtos provoca a degradação da resina, facilitando a sua pigmentação.

O objetivo deste trabalho foi avaliar três marcas comerciais de resinas compostas, em contato direto com soluções corantes, com o propósito de observar o grau de pigmentação apresentado entre os materiais durante um determinado período de tempo.

\section{Materiais e métodos}

A metodologia deste trabalho foi baseada em estudos relatados na literatura por Susin e Maixner (2001), Carreira e Vieira (2002), Minelli et al. (1988), Dinelli et al. (1995).

Para a realização deste trabalho foram utili- 
zadas as resinas compostas: Charisma (HeraeusKulzer), Durafill VS (Heraeus- Kulzer) e Fill Magic Condensável (Vigodent), sendo confeccionados 25 corpos-de-prova com cada material selecionado, na cor B2, segundo a escala de cor do fabricante de cada resina composta. Para a confecção desses corpos-de-prova foi utilizada uma matriz metálica com um orifício central medindo $2 \mathrm{~mm}$ de espessura e $6 \mathrm{~mm}$ de diâmetro. A inserção do material foi feita em incremento único, com a utilização de uma espátula Thompson (TD4x). A fotopolimerização dos corpos-de-prova foi realizada com o aparelho Optilux 401 (Demetron Res.Corp.) durante o tempo de 40 segundos. Foi interposta uma tira de poliéster (3M) entre a resina composta e o fotopolimerizador. A intensidade de luz do aparelho foi medida por um radiômetro (Cure RiteEFOS), apresentando $450 \mathrm{~mW} / \mathrm{cm}^{2}$. Os 25 corposde-prova de cada resina composta foram divididos em 5 espécimes para cada solução corante. Esses foram imersos nos seguintes corantes selecionados: - 20ml de solução de café (duas colheres de café solúvel Nescafé® para $60 \mathrm{ml}$ de água);

- 20 ml de solução de vinho tinto (Campo Largo $\left.{ }^{\circledR}\right)$;

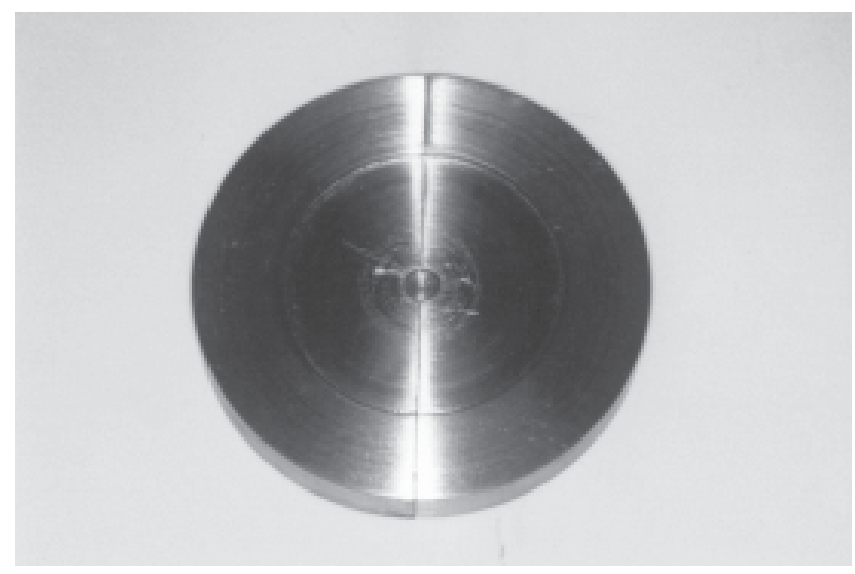

Figura 1 - Matriz de aço
- 20ml de solução de chá-preto (um saquinho de Mate-Leão® para $60 \mathrm{ml}$ de água).

- 20ml de refrigerante (Coca-Cola $\left.{ }^{\circledR}\right)$;

- 20ml de água destilada (grupo controle).

O armazenamento dos corpos-de-prova foi feito em estufa a $37^{\circ} \mathrm{C}$, em frascos opacos que não permitiam a passagem de luz. As trocas das soluções foram feitas a cada 24 horas. A observação e a documentação fotográfica foram realizadas sob luz artificial fluorescente nos tempos de 1 hora, 24 horas, 72 horas, e 1 semana após a data de imersão. As amostras foram analisadas separadamente, de acordo com a escala de cores das resinas compostas selecionadas e sob a iluminação já citada, em fundo de tecido azul. As fotografias coloridas de cada grupo da amostra foram realizadas com câmera fotográfica Dental EYE P (Yashica), e filme Kodak color iso 100. A partir da observação dos corposde-prova e da documentação fotográfica dos mesmos, foi possível determinar a alteração de cor das resinas compostas, comparando-se a cor original (B2) com a tonalidade registrada em cada um dos períodos de avaliação.

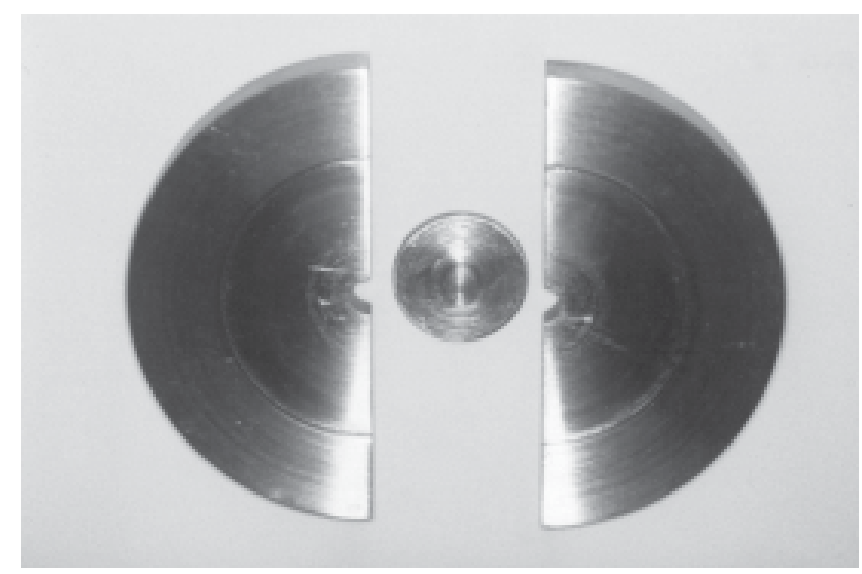

Figura 2 - Matriz de aço aberta 
16

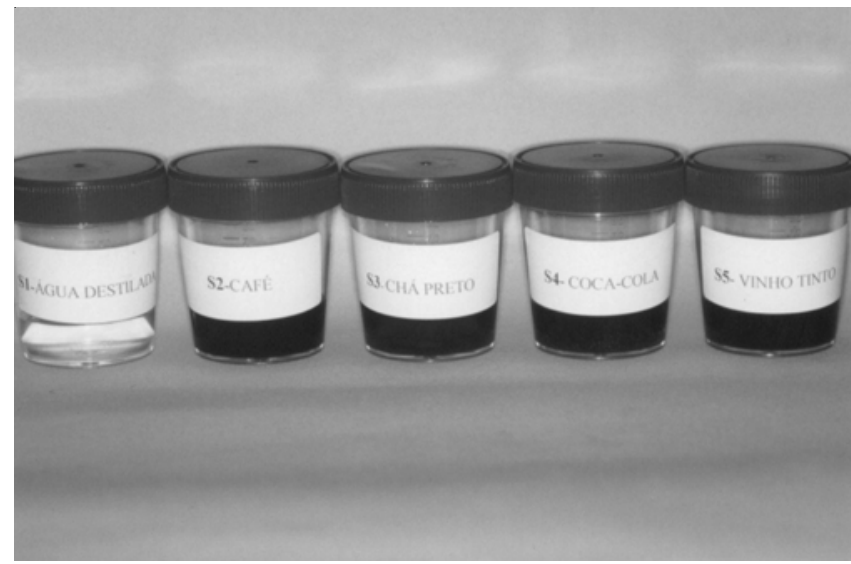

Figura 3 - Soluções corantes

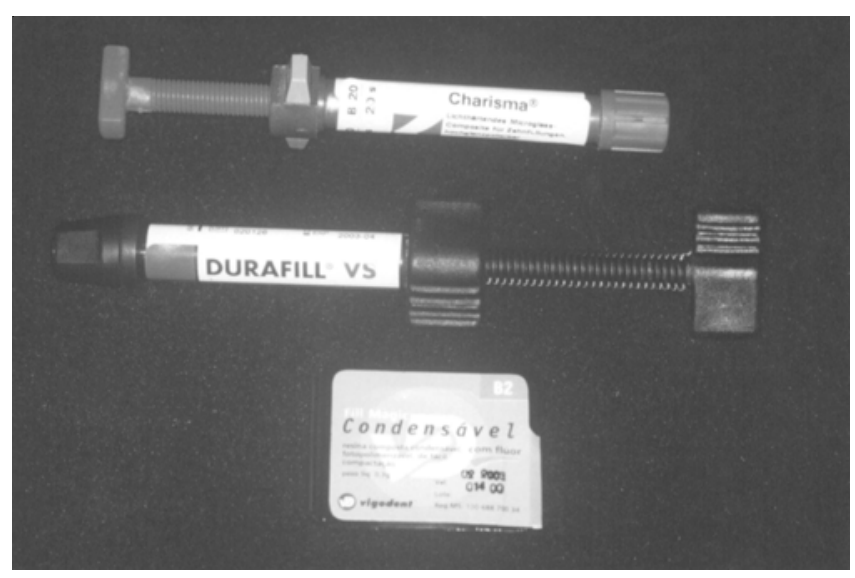

Figura 4 - Resinas Compostas

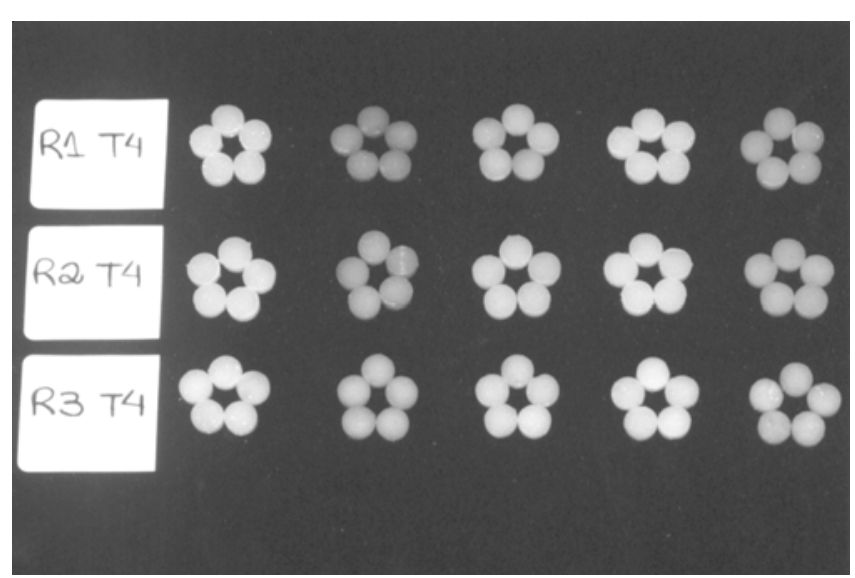

Figura 5 - Alteração de cor das resinas compostas após 1 semana de imersão (R1=Charisma- Heraeus-Kulzer; R2=Durafill VS- Heraeus-Kulzer; R3=Fill Magic Condensável- Vigodent)

\section{Resultados e discussão}

Os pacientes apresentam uma preocupação quanto ao potencial de pigmentação das restaurações estéticas, devido à ingestão freqüente de alimentos corantes (CHAN et al., 1980). Com a grande variedade de produtos no mercado odontológico testamos neste trabalho três marcas comerciais de resinas compostas que são bastante utilizadas nos consultórios odontológicos, objetivando identificar se existem diferenças entre elas quanto à pigmentação.

Entre os materiais utilizados em nosso trabalho, a resina composta Durafill VS (HeraeusKulzer) e a resina composta Charisma (HeraeusKulzer) mostraram-se altamente sensíveis ao manchamento, fato este, notado logo nas primeiras horas de observação. A resina composta Fill Magic Condensável (Vigodent) foi o material que menos sofreu a ação da pigmentação. Esses dados estão de acordo com Minelli et al. (1988), que concluiram que materiais mais ricos em fase orgânica apresentam pigmentação mais intensa, e acreditam que isso esteja relacionado com o grau de conversão desses materiais.

Entre as soluções, verificou-se que o café apresentou maior potencial de pigmentação, quando comparado com as outras soluções. A pesquisa realizada por Luce e Campbell (1988), confirma nossos resultados, quanto ao maior manchamento da solução de café sobre a solução de chá, em relação à alteração de cor de alguns materiais incluídos naquele experimento.

Menezes et al. (1999) e Minelli et al.(1988), em seus trabalhos dizem que o vinho apresenta maior potencial de pigmentação em relação ao café, devido a sua capacidade fermentativa. Cooley et al. (1987), concluiram que apesar da manutenção da forma de uma restauração em resina ser crítica, a manutenção da cor é vital em restaurações estéticas.

Os resultados foram analisados na forma de escores que variaram de 0 a 5 , segundo o grau de manchamento, como demonstrado abaixo: 
$0=0 \%$ de pigmentação na superfície do

$1=20 \%$ de pigmentação na superfície do material

$2=40 \%$ de pigmentação na superfície do material

$3=60 \%$ de pigmentação na superfície do material
$4=80 \%$ de pigmentação na superfície do material

$5=100 \%$ de pigmentação na superfície do material

Os quadros 1, 2, 3 ilustram os resultados da análise visual da alteração de cor das resinas compostas de acordo com a escala de cor de cada fabricante.

Quadro 1 - Alteração de cor da resina composta Fill Magic Condensável (Vigodent):

\begin{tabular}{|l|c|c|c|c|c|c|c|c|}
\hline \multicolumn{1}{|c|}{ Solução } & \multicolumn{2}{c|}{1 hora } & \multicolumn{2}{c|}{24 horas } & \multicolumn{2}{c|}{72 horas } & \multicolumn{2}{c|}{1 semana } \\
\hline & cor & escore & cor & escore & cor & escore & cor & escore \\
\hline Água & B2 & 0 & B2 & 0 & B2 & 0 & B2 & 0 \\
\hline Café & A3 & 3 & A3 & 3 & - & 4 & - & 4 \\
\hline Chá mate & C2 & 1 & C2 & 1 & A3 & 2 & - & 3 \\
\hline Coca-Cola & B2 & 0 & C2 & 1 & B2 & 1 & A3 & 1 \\
\hline Vinho & A3 & 2 & A3 & 3 & - & 3 & - & 4 \\
\hline
\end{tabular}

Quadro 2 - Alteração de cor da resina composta Charisma (Heraeus- Kulzer):

\begin{tabular}{|l|c|c|c|c|c|c|c|c|}
\hline \multicolumn{1}{|c|}{ Solução } & \multicolumn{2}{c|}{1 hora } & \multicolumn{2}{c|}{24 horas } & \multicolumn{2}{c|}{72 horas } & \multicolumn{2}{c|}{1 semana } \\
\hline & cor & escore & cor & escore & cor & escore & cor & escore \\
\hline Água & B2 & 0 & B2 & 0 & B2 & 0 & B2 & 0 \\
\hline Café & A3,5 & 3 & C4 & 4 & C4 & 5 & C4 & 5 \\
\hline Chá mate & B3 & 2 & B3 & 2 & A3,5 & 3 & C4 & 3 \\
\hline Coca-Cola & B2 & 0 & C2 & 1 & C2 & 2 & C2 & 2 \\
\hline Vinho & A3 & 2 & C4 & 3 & C4 & 4 & C4 & 5 \\
\hline
\end{tabular}

Quadro 3 - Alteração de cor da resina composta Durafill VS (Heraeus-Kulzer):

\begin{tabular}{|l|c|c|c|c|c|c|c|c|}
\hline \multicolumn{1}{|c|}{ Solução } & \multicolumn{2}{c|}{1 hora } & \multicolumn{2}{c|}{24 horas } & \multicolumn{2}{c|}{72 horas } & \multicolumn{2}{c|}{1 semana } \\
\hline & cor & escore & cor & escore & cor & escore & cor & escore \\
\hline Água & B2 & 0 & B2 & 0 & B2 & 0 & B2 & 0 \\
\hline Café & A3,5 & 3 & C4 & 4 & C4 & 5 & C4 & 5 \\
\hline Chá mate & B3 & 1 & A3,5 & 2 & C4 & 3 & C4 & 3 \\
\hline Coca-Cola & A3 & 1 & B3 & 1 & A3,5 & 2 & A4 & 2 \\
\hline Vinho & A4 & 2 & 0 A3,5 & 3 & C4 & 5 & C4 & 5 \\
\hline
\end{tabular}


Análise das resinas compostas em relação aos escores:

Gráfico 1 - Comparação do grau de manchamento das três resinas compostas após 1 hora de imersão nas soluções corantes:

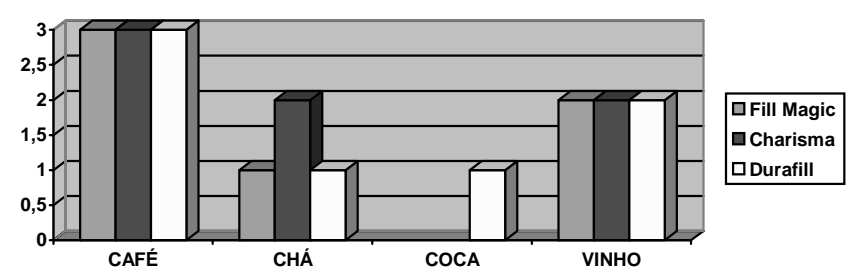

De acordo com o gráfico 1 constatou-se que a resina composta Charisma (Heraeus-Kulzer) apresentou maior grau de manchamento em imersão no chá (40\%), e que quando imersas em Coca-Cola ${ }^{\circledR}$, a única que apresentou manchamento (20\%) foi a resina composta Durafill VS ( Heraeus-Kulzer).

Gráfico 2 - Comparação do grau de manchamento das três resinas compostas após 24 horas de imersão nas soluções corantes:

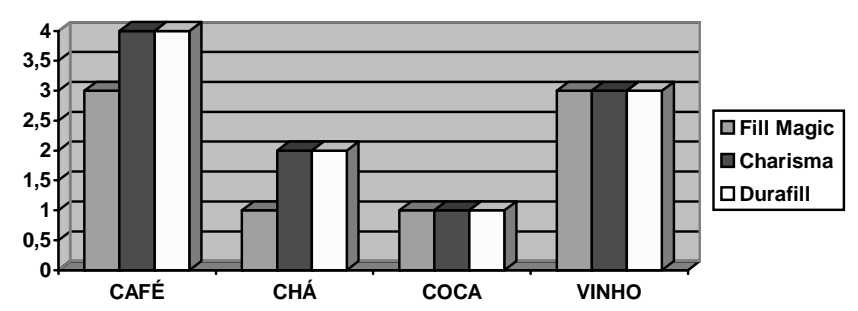

De acordo com o gráfico 2, a resina composta Fill Magic condensável (Vigodent) apresentou menor grau de manchamento em relação às outras resinas, quando imersa em café (40\%) e chá (20\%). A solução de Coca-Cola ${ }^{\circledR}$ foi a que apresentou o menor grau de pigmentação em 24 horas de imersão (20\%), ao contrário da solução de café que apresentou o maior grau de pigmentação (80\%).

Gráfico 3 - Comparação do grau de manchamento das três resinas compostas após 72 horas de imersão nas soluções corantes

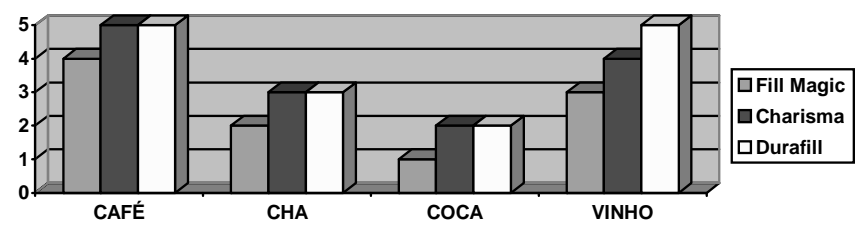

De acordo com o gráfico 3, a resina composta Fill Magic Condensável (Vigodent) apresentou o menor grau de manchamento em todas as soluções (café-80\%, chá-40\%, Coca-Cola ${ }^{\circledR}-20 \%$ e vinho-60\%). Comparando as resinas Durafill (Heraeus-Kulzer) e Charisma (Heraeus-Kulzer) a única solução que apresentou diferença de manchamento foi o vinho, sendo que a resina Durafill (Heraeus-Kulzer) foi a mais pigmentada.

Gráfico 4 - Comparação do grau de manchamento das três resinas compostas após 1 semana de imersão nas soluções corantes

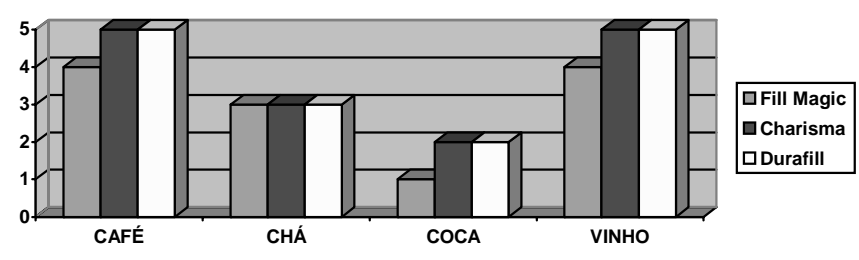

De acordo com o gráfico 4, o chá foi a única solução que apresentou o mesmo grau de manchamento para as três resinas compostas. Nas outras soluções, novamente a resina composta Fill Magic condensável (Vigodent) apresentou o menor manchamento.

\section{Considerações finais}

De acordo com a metodologia empregada neste estudo, os resultados obtidos possibilitaram concluir que:

1- A resina composta Fill Magic Condensável (Vigodent), apresentou menor pigmentação em relação à resina Charisma (Heraeus-Kulzer) e à Durafill VS (Heraeus-Kulzer);

2- Entre as soluções utilizadas no trabalho, a que apresentou o maior potencial de pigmentação foi o café e em seguida o vinho tinto, em cada material selecionado;

3- Nos três materiais utilizados, a solução que apresentou o menor grau de pigmentação foi a Coca-Cola. 


\section{REFERÊNCIAS}

1 BARATIERI, L.N. et al. Dentística-Procedimentos preventivos e restauradores. 1992.

2 CARREIRA, A. J. e VIEIRA, D. Profundidade de polimerização e grau de pigmentação de uma resina composta. Rev. Jada-Brasil.v. 5, p. 58-63, jan./fev. 2002.

3 DINELLI, W.; MACHADO, M. S.; ANDRADE, M. F; LOFFREDO, L. C. M. Estudo da influência da retenção de corantes na translucidez de resinas compostas.Efeito de materiais, tempo e meios de imersão. Rev. ABO. Nac. v. 2. n. 6, p. 422-426, dez. 1994/jan. 1995.

4 LUCE, M.S; CAMPBELL, S.F. Stain potential of for microfilled composites. J. Prosthet. Dent. v. 60, n. 2, p. 151154, aug.1988.
5 MAIXNER, A. O. e SUSIN, A. H. Avaliação da alteração de cor de resina composta submetida à ação de corantes de gêneros alimentícios. Ver. Dentística on line. ano 1, n. 2, jan./fev. 2001.

6 MENEZES, C.C.; NAMEN, M. F.; SÉRGIO, P. P. Manchamento em resinas compostas híbridas- ação dos agentes polidores. RBO. v. 56, n. 5, p. 239-241, set./out. 1999.

7 MINELLI, C.J.; CHAVES, P. H. F.; SILVA, E. M. Alteração da cor de resinas compostas. (parte I). Influência das soluções de café, chá e vinho. Rev. Odonto.USP, v. 2, n. 3, p.143-147, jul./set. 1988.

8 CHAN, K.C. et al. The ability of foods to stain two composite resins. J. Prosth Dentistry, v. 43, n. 5, p. 542-545, may 1980.

9 COOLEY, K.L. et al. Staining of posterior resin restorative materials. Quintessence Int, 18[12]: 823-7, dec. 1987. 